\title{
CGFe and TGF- $\beta 1$ enhance viability and osteogenic differentiation of human dental pulp stem cells through the MAPK pathway
}

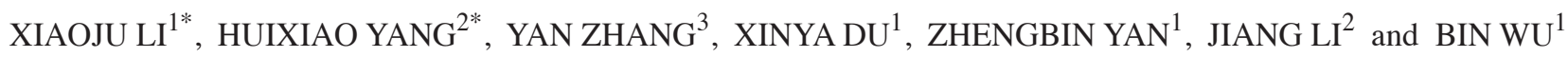 \\ ${ }^{1}$ Department of Stomatology, The People's Hospital of Longhua, Shenzhen, Guangdong 518109; \\ ${ }^{2}$ Key Laboratory of Oral Medicine, Guangzhou Institute of Oral Disease, Stomatological Hospital of \\ Guangzhou Medical University, Guangzhou, Guangdong 510140; ${ }^{3}$ Department of General Therapy Dentistry, \\ Stomatology Hospital of Jilin University, Changchun, Jilin 130021, P.R. China
}

Received February 14, 2021; Accepted July 2, 2021

DOI: 10.3892/etm.2021.10482

\begin{abstract}
The present study aimed to evaluate the effects of concentrated growth factor exudate (CGFe) and TGF- $\beta 1$ on the viability and osteogenic differentiation of human dental pulp stem cells (hDPSCs). CGFe was prepared from the peripheral blood of healthy donors (obtained with informed consent). STRO $-1^{+}$hDPSCs were isolated from dental pulp tissues and treated in four groups: i) Control; ii) TGF- $\beta 1$ (1 ng/ml); iii) 100\% CGFe; and iv) TGF- $\beta 1$ ( $1 \mathrm{ng} / \mathrm{ml})+100 \%$ CGFe group. hDPSC viability was measured via MTT assay. The osteogenic differentiation of hDPSCs was quantified via alkaline phosphatase (ALP) activity, western blotting and reverse transcription-quantitative PCR assays. CGFe and TGF- $\beta 1$ enhanced hDPSC viability, upregulated ALP activity, upregulated the expression of phosphorylated (p)-ERK1/2, p-JNK and p-p38 in hDPSCs, and promoted transcription and protein expression of osteogenic-related genes (bone sialoprotein, Runt-related transcription factor 2 and osteocalcin) in hDPSCs. The present study demonstrated that CGFe and TGF- $\beta 1$ facilitated the viability and osteogenic differentiation of hDPSCs potentially through activation of the MAPK signaling pathway.
\end{abstract}

\section{Introduction}

Increasing interest has arisen for the study of periodontitis and chronic apical periodontitis, which cause irreversible destruction of periodontal support tissues, including the alveolar bone,

Correspondence to: Dr Zhengbin Yan, Department of Stomatology, The People's Hospital of Longhua, 38 Jinglong Jianshe Road, Longhua, Shenzhen, Guangdong 518109, P.R. China

E-mail: yanzhengbin@163.com

*Contributed equally

Key words: concentrated growth factor exudate, transforming growth factor- $\beta 1$, human dental pulp stem cells, viability and osteogenic differentiation, mitogen-activated protein kinase signaling pathway the periodontal ligament and the root cementum $(1,2)$. Several systemic diseases, such as diabetes, endocrine disease and hypertension, are the main causes of tooth loss (2). The combination of membranes and fillers, demineralized freeze-dried bone allografts, bovine-derived xenografts and barrier membranes have been adopted in modern clinical practice to treat periodontitis and chronic apical periodontitis; however, only a small number of these therapies have been accepted as regenerative techniques, and most have had limited success and generally unsatisfactory outcomes (2). Therefore, it is of great interest to find better treatments for periodontitis and chronic apical periodontitis.

Human dental pulp stem cells (hDPSCs) and appropriate growth factors, such as TGF- $\beta 1$, are necessary for functional periodontal tissue regeneration (3). hDPSCs are an undifferentiated mesenchymal cell type in dental pulp that differentiate into a variety of cells, such as those which form dentin (4). In recent years, the MAPK signaling pathway has been widely investigated in the fields of cell proliferation, differentiation and apoptosis (5). Concentrated growth factor (CGF) is known to be enriched in growth factors and fibrin (5-7). CGF is a gel-like substance that can be obtained by centrifugation of venous blood (7). CGF combined with bone graft material was indicated to promote immediate periodontal tissue regeneration and osteogenic differentiation (5-7). CGF exudate (CGFe) is extracted from CGF and used in research experiments to study the effects of CGF in vitro (1). Previous studies have indicated that CGFe shortened the duration before osteogenesis onset in the operational area of periodontal tissue and notably improved the quality of bone formation (6-8). For instance, Park et al (8) reported that CGFe stimulated the proliferation of beagle periodontal ligament stem cells in vitro.

TGF- $\beta$ is a multifunctional cytokine involved in the regulation of cell proliferation, migration, differentiation, apoptosis and extracellular matrix formation $(9,10)$. It also plays an important role in bone repair, vascular regeneration and immune system regulation $(9,10)$. TGF- $\beta$ family includes three homologous isoforms, namely TGF- $\beta 1$, TGF- $\beta 2$ and TGF- $\beta 3$. Among these, TGF- $\beta 1$ is the most abundant and widely distributed $(9,10)$. It also has been indicated to induce mesenchymal stem cells to differentiate into osteoblasts by recruiting osteoblasts and coupling them to promote bone 
tissue reconstruction (11). The combination of TGF- $\beta 1$ and platelet-derived growth factor (PDGF) has been demonstrated to induce osteogenesis in osteoblast-like cells, and TGF- $\beta 1$ at a concentration of $5 \mathrm{ng} / \mathrm{ml}$ promoted the formation of mineralized nodules (12). A previous study has indicated that TGF- $\beta 1$ induced exfoliated deciduous tooth stem cells to overexpress bone sialoprotein (BSP) and osteocalcin (OCN) (13).

The aim of the present study was to assess the effects of CGFe and TGF- $\beta 1$ on hDPSC proliferation and osteogenic differentiation in order to discover improved treatments for periodontitis and chronic apical periodontitis. Specifically, the effects of CGFe and TGF- $\beta 1$ were examined on the enhancement of alkaline phosphatase (ALP) activity and the expression levels of BSP, Runt-related transcription factor 2 (RUNX2) and OCN in hDPSCs.

\section{Materials and methods}

hDPSC isolation and culture. All experiments reported in the present study were approved by the Ethics Committee of the Stomatological School of Jilin University (Changchun, China). Dental pulp tissues were obtained from healthy individuals (3 females and 3 males; age, 12-18 years; without systemic disease) with informed consent from their parents, between March 2019 and December 2019. The dental pulp tissue samples were collected from third molar extractions at Jilin University Health Science Center (Changchun, China). Dental pulp stem cells were isolated and cultured following procedures described previously (14). The dental pulp matrix was gently removed from the tooth, minced with ophthalmic scissors and digested in a solution containing $3 \mathrm{mg} / \mathrm{ml}$ collagenase type I (Sigma-Aldrich; Merck KGaA) and $4 \mathrm{mg} / \mathrm{ml}$ Dispase ${ }^{\circledR}$ II (Roche Diagnostics $\mathrm{GmbH}$ ) at $37^{\circ} \mathrm{C}$ for $60 \mathrm{~min}$. The cells were purified using a mouse anti-STRO- $1^{+}$antibody $\left(1: 200 ; 4^{\circ} \mathrm{C}\right.$; 3 h; cat. no. sc-4773; Santa Cruz Biotechnology, Inc.) and goat anti-mouse IgG Dynabeads (1:500; $4^{\circ} \mathrm{C} ; 2$ h; cat. no. 11201D; Invitrogen; Thermo Fisher Scientific, Inc.) according to the manufacturer's instructions. The purified hDPSCs were cultured in $\alpha$-minimum essential medium ( $\alpha$-MEM; Gibco; Thermo Fisher Scientific, Inc.) supplemented with 10\% FBS (Gibco; Thermo Fisher Scientific, Inc.) as well as $100 \mathrm{U} / \mathrm{ml}$ streptomycin and $100 \mathrm{mg} / \mathrm{ml}$ penicillin (Gibco; Thermo Fisher Scientific, Inc.) at $37^{\circ} \mathrm{C}$ in $5 \% \mathrm{CO}_{2}$. The medium was changed every 3 days, and hDPSCs were passaged by trypsinization (Gibco; Thermo Fisher Scientific, Inc.) until they reached $80 \%$ confluence. hDPSCs between passages 3-6 were used for the experiments of the present study.

Immunocytochemistry staining. hDPSCs $\left(1 \times 10^{5}\right.$ cells $)$ at passage 4 were seeded into six-well plates covered in advance with coverslips, and incubated for $72 \mathrm{~h}$ at $37^{\circ} \mathrm{C}$. The cells were then rinsed three times with $0.01 \mathrm{M}$ PBS and fixed with $4 \%$ paraformaldehyde for $15 \mathrm{~min}$ at room temperature. Endogenous peroxidase activity was eliminated by incubation with $3 \% \mathrm{H}_{2} \mathrm{O}_{2}$ for $15 \mathrm{~min}$ at room temperature. The cells were then incubated with anti-vimentin (1:100; 2 h; cat. no. ab24525; Abcam) and anti-cytokeratin-15 primary antibodies (1:200; 2 h; cat. no. AM06387SU-N; OriGene Technologies, Inc.) at $4^{\circ} \mathrm{C}$. hDPSCs were subsequently incubated with secondary goat-anti-rabbit, goat-anti-mouse and goat anti-chicken IgG were AlexaFluor 488 (cat. no. A-11008; Invitrogen; Thermo Fisher Scientific, Inc.), 568 (cat. no. A-11004; Invitrogen; Thermo Fisher Scientific, Inc.), and 647 (cat. no. A-21449; Invitrogen; Thermo Fisher Scientific, Inc.) labeled, respectively; and used in various combinations at a 1:1,000 dilution at $4^{\circ} \mathrm{C}$ (15). The SP (no. SNM500; OriGene Technologies, Inc.) immunohistochemistry assay kit (OriGene Technologies, Inc.) was used for immunocytochemical staining according to the manufacturer's protocol, and 3,3'-diaminobenzidine (OriGene Technologies, Inc.) was used to stain positive cells, which were imaged using a fluorescent microscope (IX73; Olympus Corporation; magnification, x400;) (15). The blue color of the nuclei in Fig. 1 was produced by hematoxylin staining for $5 \mathrm{~min}$ at $25^{\circ} \mathrm{C}$.

Preparation of CGFe and TGF- $\beta 1$. CGFe was obtained from four healthy male donors (aged 22-30 years) visiting the outpatient clinic at the Health Science Center of Jilin University (Changchun, China) between March and September 2019, with their informed consent. According to an existing protocol (15), a 5-ml venous blood sample was collected from each donor, and the blood samples were used to produce CGF and CGFe. The blood samples were centrifuged at $750 \times \mathrm{g}$ for $12 \mathrm{~min}$ at $4^{\circ} \mathrm{C}$. A white CGF clot was formed between acellular plasma and red blood cells (RBCs), which was separated from the RBCs using scissors, placed on an endo box and compressed by the endo box cover. The CGF clot was converted into CGFe by applying pressure. CGFe was filtered using a $0.22-\mu \mathrm{m}$ sterile syringe filter unit (MilliporeSigma), and the pooled CGFe samples were stored at $-80^{\circ} \mathrm{C}$. The original concentration of CGFe was defined as 100,50 and $25 \%$ concentrations of CGFe were obtained by dilution of the $100 \%$ CGFe with $\alpha$-MEM. As observed in the present study, the CGF membrane used in clinical treatment were completely absorbed in 7 to 14 days, day 7 and 14 were selected as two monitoring time points for reporting the results in the present experiments.

TGF- $\beta 1$ powder (PeproTech China) was dissolved in distilled water according to the manufacturer's instructions, and different dilutions of TGF- $\beta 1$ were stored at $-80^{\circ} \mathrm{C}$ for subsequent experiments.

MTT assay. MTT was used to quantify the effects of CGFe and TGF- $\beta 1$ on hDPSC viability. hDPSCs $\left(3 \times 10^{3}\right.$ cells/well $)$ were seeded into 96 -well plates (Corning, Inc.) in $10 \%$ FBS complete medium $(\alpha-\mathrm{MEM})$ and incubated for $24 \mathrm{~h}$ at $37^{\circ} \mathrm{C}$. hDPSCs were then exposed to TGF- $\beta 1$ (at concentrations of $0,1,5,10$ and $20 \mathrm{ng} / \mathrm{ml}$ ) for 7 days. After 7 days of culture, MTT reagent $(10 \mu \mathrm{l})$ was added to the culture medium of each well, followed by incubation at $37^{\circ} \mathrm{C}$ for $4 \mathrm{~h}$. The medium was removed and the cells were washed twice with 0.01 M PBS. DMSO (Sigma-Aldrich; Merck KGaA) was added into each well to dissolve the formazan crystals. The optical density (OD) values were measured using an automatic ELISA reader (ELx800; BioTek Instruments, Inc.) at $490 \mathrm{~nm}$. The assay was repeated three times under the same conditions, and the data are presented as the mean \pm SD. hDPSCs in $10 \%$ FBS complete medium ( $\alpha$-MEM) were used as the control group.

In another experiment, hDPSCs were divided into four groups: i) TGF- $\beta 1$ ( $1 \mathrm{ng} / \mathrm{ml})$; ii) $25 \% \mathrm{CGFe}+\mathrm{TGF}-\beta 1$ (1 ng/ml); iii) $50 \%$ CGFe + TGF- $\beta 1(1 \mathrm{ng} / \mathrm{ml})$; and iv) $100 \%$ 

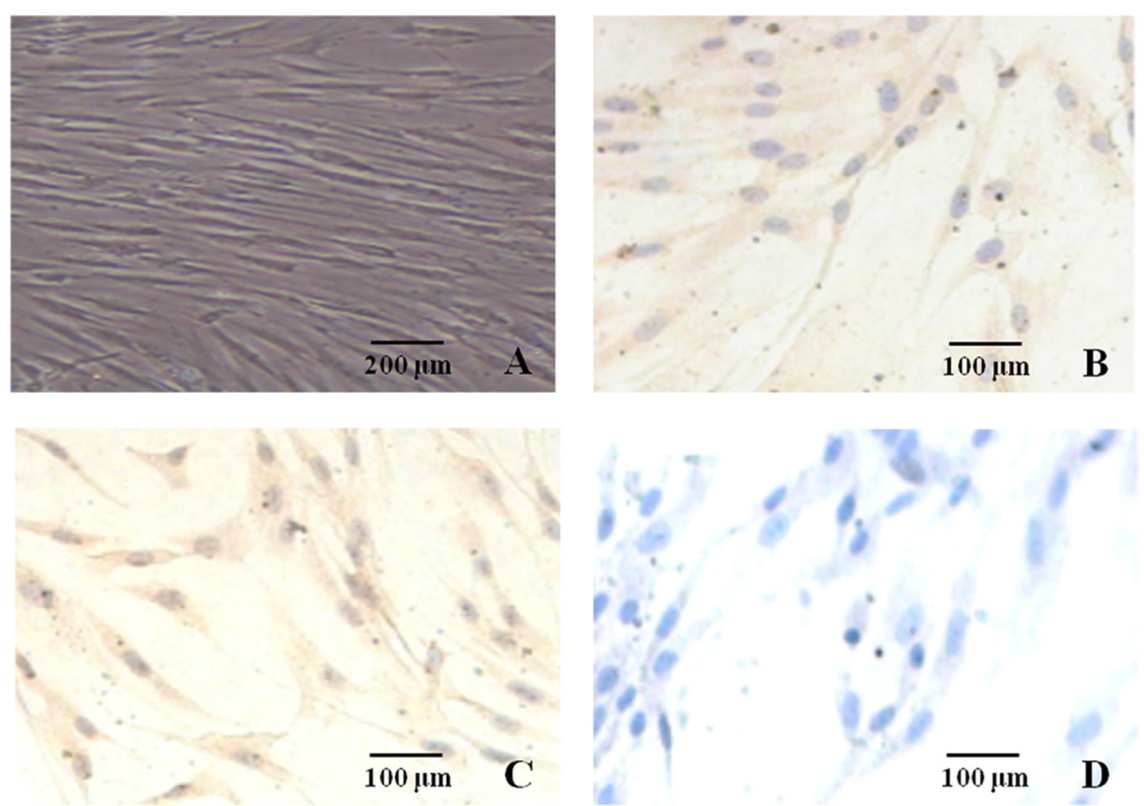

Figure 1. Identification and characterization of hDPSCs. (A) Primary hDPSCs presented a spindle shape. Scale bar, $200 \mu \mathrm{m}$. Immunocytochemistry staining was (B) positive for STRO-1, (C) positive for vimentin and (D) negative for cytokeratin-15. Scale bar, $100 \mu \mathrm{m}$. hDPSCs, human dental pulp stem cells.

CGFe + TGF- $\beta 1(1 \mathrm{ng} / \mathrm{ml})$ group, and subsequently incubated for 7 days. MTT assay was performed as aforementioned.

ALP activity assay. hDPSCs $\left(1 \times 10^{4}\right.$ cells/well) were seeded into 24-well plates (Corning, Inc.) and incubated for $24 \mathrm{~h}$ at $37^{\circ} \mathrm{C}$. Subsequently, the cells were exposed to $100 \% \mathrm{CGFe}$, TGF- $\beta 1(1 \mathrm{ng} / \mathrm{ml})$ or TGF- $\beta 1(1 \mathrm{ng} / \mathrm{ml})+100 \%$ CGFe for 7 or 14 days. hDPSCs in 10\% FBS complete medium ( $\alpha$-MEM) were used as the control group. At the given time points, the cells were lysed using $0.1 \%$ Triton X-100, and the lysates were centrifuged at $8,000 \mathrm{x}$ g for $10 \mathrm{~min}$ at $4^{\circ} \mathrm{C}$. The supernatant was added to 96 -well plates ( $50 \mu \mathrm{l} / \mathrm{well})$, and ALP activity was examined using the ALP assay kit (cat. no. A059-2; Nanjing Jiancheng Bioengineering Institute). The OD values were measured using an automatic microplate reader (Infinite 200 PRO; Tecan Group, Ltd.) at $520 \mathrm{~nm}$. The assay was repeated three times under the same conditions, and the data were presented as the mean $\pm \mathrm{SD}$.

Reverse transcription-quantitative PCR (RT-qPCR). hDPSCs $\left(1 \times 10^{5}\right.$ cells/well) were seeded into six-well plates with standard medium ( $\alpha$-MEM) until they reached $60-70 \%$ confluence. The cells were treated with four different media: The control group was treated with osteogenesis-inducing medium [ $\alpha$-MEM supplemented with $50 \mu \mathrm{g} / \mathrm{ml}$ ascorbic acid and $10 \mathrm{mM} \beta$-sodium glycerophosphate (Sigma-Aldrich; Merck $\mathrm{KGaA}$ )]; the three experimental groups were treated with osteogenesis-inducing medium supplemented with $100 \%$ CGFe, TGF- $\beta 1$ ( $1 \mathrm{ng} / \mathrm{ml})$ or $100 \%$ CGFe + TGF- $\beta 1(1 \mathrm{ng} / \mathrm{ml})$.

Total RNA was extracted using TRIzol ${ }^{\circledR}$ reagent (Invitrogen; Thermo Fisher Scientific, Inc.) and reverse transcribed into cDNA on the 7 and 14th day after treatment. cDNA synthesis was performed with $1 \mu \mathrm{g}$ total RNA using SuperScript ${ }^{\mathrm{TM}}$ II Reverse Transcriptase and random hexamer primers (cat. no. 18064014; Invitrogen; Thermo Fisher Scientific, Inc.). The following temperature protocol was used for reverse transcription: Room temperature for $10 \mathrm{~min}, 37^{\circ} \mathrm{C}$ for $60 \mathrm{~min}$ and $85^{\circ} \mathrm{C}$ for $5 \mathrm{~min}$.

An aliquot $(2 \mu \mathrm{l})$ of each sample was used for qPCR determination of the expression of the osteogenic genes $B S P$, $R U N X 2$ and $O C N$ using the $\mathrm{SYBR}^{\circledR}$ Premix Ex Taq ${ }^{\mathrm{TM}}$ II kit (Takara Bio, Inc.). qPCR was performed in a Rotor-Gene $\mathrm{Q}$ thermocycler as follows: $95^{\circ} \mathrm{C}$ for $3 \mathrm{~min}$, followed by 40 cycles of $95^{\circ} \mathrm{C}$ for $3 \mathrm{sec}$ and $60^{\circ} \mathrm{C}$ for $60 \mathrm{sec}$. Each experiment was repeated three times, and the $2^{-\Delta \Delta C q}$ method was used to calculate the fold differences in gene expression (16), using $\beta$-actin for normalization. The primers used are listed in Table I.

Western blotting. hDPSC protein lysates were prepared using RIPA buffer with pH 7.4 (10 mM Tris-Cl, 1 mM PMSF, $150 \mathrm{mM} \mathrm{NaCl}, 0.1 \%$ SDS, $1 \%$ sodium deoxycholate and $1 \%$ Triton X-100). The cells were treated with four different media [control, $100 \%$ CGFe, TGF- $\beta 1(1 \mathrm{ng} / \mathrm{ml})$ or $100 \%$ CGFe + TGF- $\beta 1(1 \mathrm{ng} / \mathrm{ml})]$ for 7 days. The cell lysates were incubated on ice for $30 \mathrm{~min}$, then clarified by centrifugation at $6,000 \mathrm{x} \mathrm{g}$ at $4^{\circ} \mathrm{C}$ for $10 \mathrm{~min}$. The protein contents were quantified with a BCA assay kit. Protein samples $(20 \mu \mathrm{g})$ were denatured and resolved by $10 \%$ SDS-PAGE and transferred onto PVDF membranes (MilliporeSigma) at $300 \mathrm{~mA}$ for $2 \mathrm{~h}$ at $4^{\circ} \mathrm{C}$. The membranes were blocked with $5 \%$ non-fat milk at room temperature for $1 \mathrm{~h}$, and subsequently incubated with the following primary antibodies: Anti-RUNX2 (1:1,000; cat. no. 12556; Cell Signaling Technology, Inc.), anti-BSP (1:1,000; cat. no. ab92920; Abcam), anti-OCN (1:1,000; cat. no. ab93876; Abcam); anti-ERK1/2 (1:1,000; cat. no. BS3628; Bioworld Technology, Inc.), anti-phosphorylated (p)-ERK1/2 (1:1,000; cat. no. BS4759; Bioworld Technology, Inc.), anti-JNK (1:1,000; cat. no. BS3631; Bioworld Technology, Inc.), anti-p-JNK (1:1,000; cat. no. BS4763; Bioworld Technology, Inc.), anti-p38 (1:1,000; cat. no. BS9851M Bioworld Technology, Inc.), anti-p-p38 (1:1,000; cat. no. BS4635; Bioworld Technology, 
Table I. Primers used for reverse transcription-quantitative PCR analysis.

\begin{tabular}{lllr}
\hline Gene & \multicolumn{1}{c}{ Forward primer (5'-3') } & \multicolumn{1}{c}{ Reverse primer (5'-3') } & PCR product (bp) \\
\hline$\beta$-actin & AGAAAATCTGGCACCACACC & GGGTGTTGAAGGTCTAAA & 139 \\
OCN & GGCGCTACCTGTATCAATGG & TCAGCCAACTCGTCACAGTC & 106 \\
RUNX2 & CACCATGTCAGCAAAACTTCTT & TCACGTCGCTCATTTTGC & 96 \\
BSP & GCAGTAGTGACTCATCCGAAGAA & GCCTCAGAGTCTTCATCTTCATTC & 121 \\
\hline
\end{tabular}

BSP, bone sialoprotein; RUNX2, Runt-related transcription factor 2; OCN, osteocalcin.
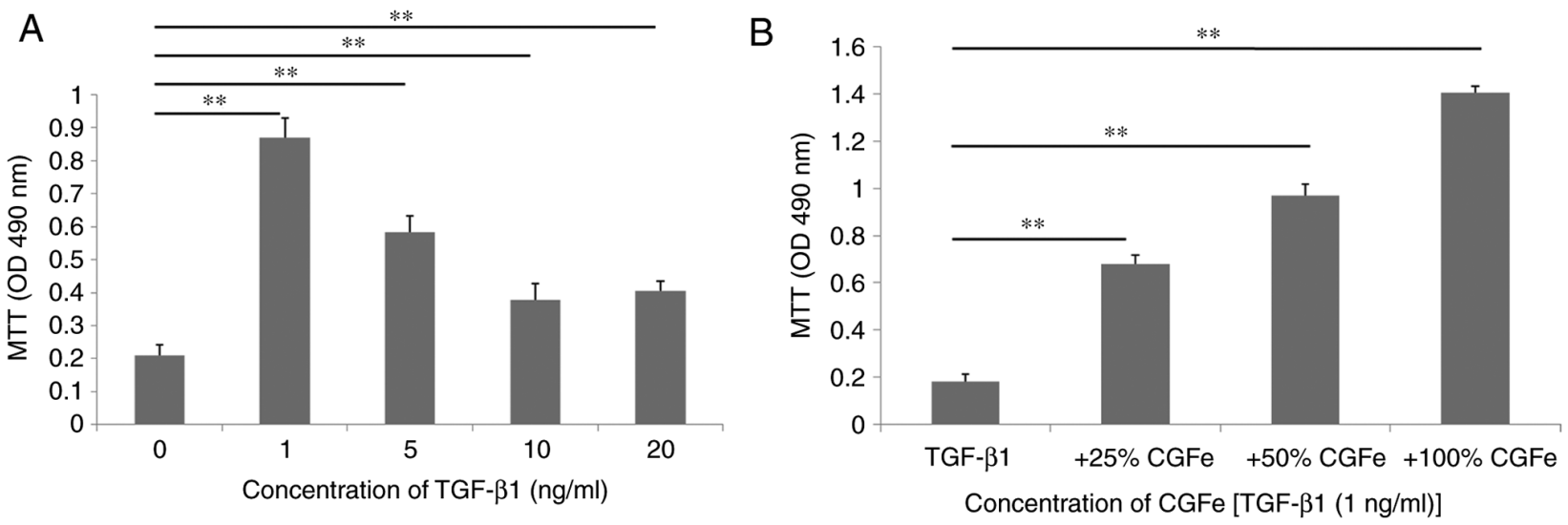

Figure 2. Viability of hDPSCs with different stimuli in vitro. (A) Effects of different concentrations of TGF- $\beta 1$ on the viability of hDPSCs in vitro. hDPSCs exhibited the strongest proliferative activity when stimulated with $1 \mathrm{ng} / \mathrm{ml}$ TGF- $\beta 1$. * $\mathrm{P}<0.01$. (B) Effects of CGFe, TGF- $\beta 1$ and CGFe + TGF- $\beta 1$ on the viability of hDPSCs in vitro, examined with different concentrations of CGFe and $1 \mathrm{ng} / \mathrm{ml}$ TGF- $\beta 1$. hDPSCs exhibited the strongest proliferative activity when stimulated with $1 \mathrm{ng} / \mathrm{ml}$ TGF- $\beta 1$ combined with $100 \%$ CGFe. ${ }^{* *} \mathrm{P}<0.01$. hDPSCs, human dental pulp stem cells; CGFe, concentrated growth factor exudate; OD, optical density.

Inc.) and anti- $\beta$-actin (1:1,000; cat. no. 6609-1-Ig; Abgent Biotech Co., Ltd.) at $4^{\circ} \mathrm{C}$ overnight. The membranes were washed in TBS containing $0.1 \%$ Tween-20 (TBST) three times and incubated with HRP-labeled secondary antibody (cat. no. SA00001-2; 1:10,000; ProteinTech Group, Inc.) for $1 \mathrm{~h}$ at $22^{\circ} \mathrm{C}$. Following three washes with TBST, the protein bands were visualized using an ECL kit (GE Healthcare) and exposed to an X-ray film. $\beta$-actin was used as internal reference, and the experiment was performed in triplicates (ImageJ v1.8.0; NIH). The protein bands (ERK1/2, p-ERK1/2, JNK, p-JNK, $\mathrm{p} 38$, and $\mathrm{p}-\mathrm{p} 38$ ) were recorded at the selected time points of 0 , 30,60 and $90 \mathrm{~min}$.

Statistical analysis. Numerical results are presented as the mean \pm SD of three independent experiments. Statistical analyses were performed using SPSS software (version 22.0; IBM Corp.). hDPSC viability, RT-qPCR and ALP activity assays were analyzed via one-way ANOVA and Tukey's multiple comparison test. Western blotting data was analyzed using one-way ANOVA followed by Bonferroni's post-hoc test for independent samples. $\mathrm{P}<0.05$ was considered to indicate a statistically significant difference.

\section{Results}

hDPSC characteristics. hDPSC morphology resembled that of fibroblast-like cells, with an elongated cell body and the nucleus located in the center. Under the light microscope, the clonal proliferating cells were closely arranged, the cell morphology was uniform and the cytoplasm was abundant (Fig. 1A). The nuclei were oval and contained distinct nucleoli. Immunocytochemical staining of in vitro culture indicated that the hDPSCs were positive for STRO-1 (Fig. 1B) and vimentin protein (Fig. 1C). The nuclei were colorless, and anti-cytokeratin staining was negative (Fig. 1D). The cytosol was not stained, which was consistent with the characteristics of mesenchymal tissue derived cells.

Effects of CGFe and TGF- $\beta 1$ on hDPSC viability. The present study was designed to examine the impact of TGF- $\beta 1$ at a range of concentrations $(0,1,5,10$ or $20 \mathrm{ng} / \mathrm{ml})$ on the viability of hDPSCs for 7 days in vitro (Fig. 2A). The viability of hDPSCs were determined using an MTT assay. TGF- $\beta 1$ at a concentration of $1 \mathrm{ng} / \mathrm{ml}$ demonstrated the best promoting effects on the viability of hDPSCs. The difference between the control and TGF- $\beta 1(1 \mathrm{ng} / \mathrm{ml})$ groups was the highest $(\mathrm{P}<0.01)$, and the difference between the control and TGF- $\beta 1$ groups $(5,10$ or $20 \mathrm{ng} / \mathrm{ml})$ was also statistically significant (all $\mathrm{P}<0.01)$. hDPSCs were exposed to TGF- $\beta 1(1 \mathrm{ng} / \mathrm{ml}), 25 \%$ CGFe + TGF- $\beta 1(1 \mathrm{ng} / \mathrm{ml}), 50 \%$ CGFe + TGF- $\beta 1(1 \mathrm{ng} / \mathrm{ml})$ or $100 \%$ CGFe + TGF- $\beta 1(1 \mathrm{ng} / \mathrm{ml})$ for 7 days (Fig. 2B). Compared with the TGF- $\beta 1(1 \mathrm{ng} / \mathrm{ml})$ group, the viability rate of the $100 \%$ CGFe + TGF- $\beta 1(1 \mathrm{ng} / \mathrm{ml})$ group increased significantly $(\mathrm{P}<0.01)$, and the $25 \%$ CGFe + TGF- $\beta 1(1 \mathrm{ng} / \mathrm{ml})$ and $50 \%$ CGFe + TGF- $\beta 1(1 \mathrm{ng} / \mathrm{ml})$ groups also demonstrated notable rate increases $(\mathrm{P}<0.01)$. 


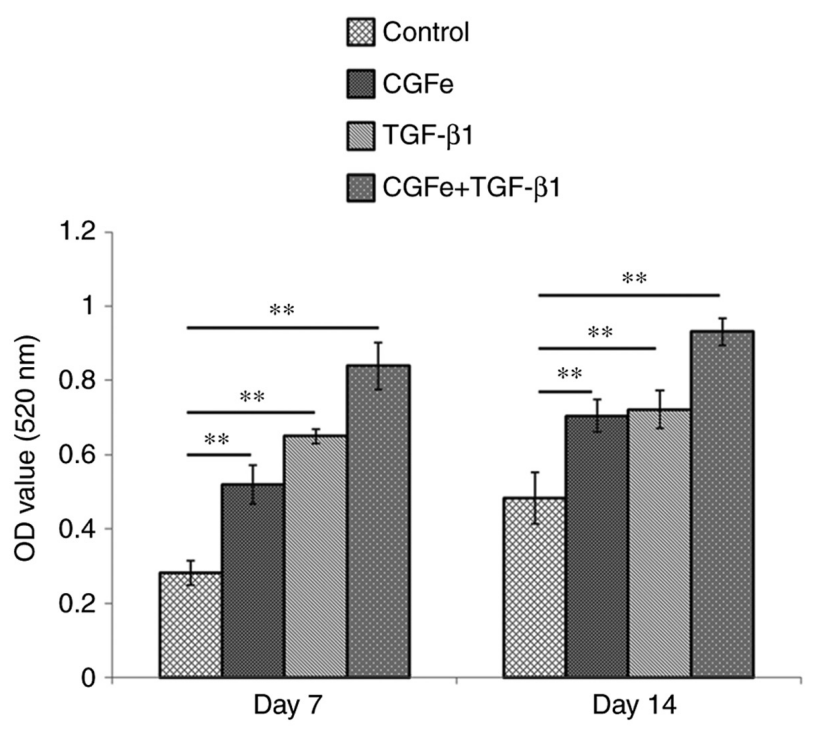

Figure 3. Effects of $100 \%$ CGFe, TGF- $\beta 1(1 \mathrm{ng} / \mathrm{ml})$ and $100 \%$ CGFe + TGF- $\beta 1$ $(1 \mathrm{ng} / \mathrm{ml})$ on ALP activity in human dental pulp stem cells. Following 7 or 14 days of culture, ALP activity in the $100 \%$ CGFe + TGF- $\beta 1(1 \mathrm{ng} / \mathrm{ml})$ group was higher than in the other groups. Moreover, compared with the control group, ALP activity in the $100 \%$ CGFe group and TGF- $\beta 1(1 \mathrm{ng} / \mathrm{ml})$ group was also increased. ${ }^{* *} \mathrm{P}<0.01$. CGFe, concentrated growth factor exudate; ALP, alkaline phosphatase; OD, optical density.

ALP activity. After 7 or 14 days of culture, hDPSCs cultured in $100 \%$ CGFe + TGF- $\beta 1(1 \mathrm{ng} / \mathrm{ml})$ demonstrated the highest levels of ALP activity compared with the other experimental groups and the control group (Fig. 3). Furthermore, the ALP activity of hDPSCs in the $100 \%$ CGFe group and the TGF- $\beta 1$ $(1 \mathrm{ng} / \mathrm{ml})$ group on the 7 and 14th days was also increased compared with the control group (all $\mathrm{P}<0.01$ ). Subsequent experiments were performed with the optimized concentrations of CGFe (100\%) and TGF- $\beta 1$ ( $1 \mathrm{ng} / \mathrm{ml})$.

Effects of CGFe and TGF- $\beta 1$ on the expression of osteogenesis-associated genes. The expression levels of osteogenesis-associated genes (RUNX2, BSP and OCN) were measured on the 7 and 14th days after treatment. On the 7th day, the expression levels of $B S P$ and $R U N X 2$ were both increased in the CGFe, the TGF- $\beta 1$ and the CGFe + TGF- $\beta 1$ group, compared with the control group, and the differences were significant (Fig. 4A and $\mathrm{B} ; \mathrm{P}<0.01$ ). The expression levels of BSP and RUNX2 were further increased on the 14th day, compared with the control group (Fig. $4 \mathrm{~A}$ and $\mathrm{B} ; \mathrm{P}<0.01$ ). The gene expression level of $O C N$ in the CGFe and the TGF- $\beta 1$ group was not increased on day 7 and 14 . However, the expression level of $O C N$ in the CGFe + TGF- $\beta 1$ group was significantly increased at both days 7 and 14 compared with the control group (Fig. 4C; $\mathrm{P}<0.01$ ).

Effects of CGFe and TGF- $\beta 1$ on osteogenic proteins and $M A P K$ signaling pathways. Western blotting was performed to examine the effect of CGFe, TGF- $\beta 1$ and CGFe + TGF- $\beta 1$ on hDPSC differentiation, as well as to confirm the RT-qPCR results at the protein level. hDPSCs were cultured in the aforementioned four different media for 7 and 14 days.

As demonstrated in Fig. 5, compared with the control group, the protein levels of RUNX2 and BSP were increased in the
CGFe, the TGF- $\beta 1$ and the CGFe + TGF- $\beta 1$ group at different time points (all $\mathrm{P}<0.01)$. Compared with the control group, the protein levels of OCN were increased in the CGFe + TGF- $\beta 1$ group $(\mathrm{P}<0.01)$, but were not significantly increased $(\mathrm{P}>0.05)$ in the CGFe group and the TGF- $\beta 1$ group.

As the present results illustrated that CGFe + TGF- $\beta 1$ treatment exhibited the most important effect on the viability and differentiation of hDPSCs, this condition was selected to examine the expression of MAPK pathway-related proteins at different time points.

No significant difference in the total protein expression of the three MAPK pathway proteins (ERK1/2, JNK and p38) was noted at the different selected time points (Fig. 6A-C). The protein expression of $\mathrm{p}$-ERK1/2 in hDPSCs increased significantly after stimulation with CGFe + TGF- $\beta 1$ for $30 \mathrm{~min}$, and decreased slightly after 60 and $90 \mathrm{~min}$ (Fig. 6A), compared with 0 min. As presented in Fig. 6D, the ratios of p-ERK1/2 to total ERK1/2 in hDPSCs after 30, 60 and 90 min were all significantly higher than that at $0 \mathrm{~min}$ (all $\mathrm{P}<0.01$ ).

The protein expression of $\mathrm{p}-\mathrm{JNK}$ in hDPSCs was also increased after 30 and $60 \mathrm{~min}$, compared with $0 \mathrm{~min}$, and then decreased to its initial expression level after $90 \mathrm{~min}$ (Fig. 6B). As indicated in Fig. 6D, the ratio of p-JNK to JNK in hDPSCs after 30 and 60 min was significantly higher than that at 0 min (both $\mathrm{P}<0.01$ ), while no significant difference was observed in hDPSCs after $90 \mathrm{~min}(\mathrm{P}>0.05)$.

The protein expression of p-p38 in hDPSCs increased progressively after stimulation with CGFe + TGF- $\beta 1$ for $90 \mathrm{~min}$, with the largest increase at $90 \mathrm{~min}$, compared with 0 min (Fig. 6C). As presented in Fig. 6D, the ratio of p-p38 to p38 in hDPSCs at 30,60 and 90 min was significantly higher than at $0 \mathrm{~min}($ all $\mathrm{P}<0.01)$.

In the $100 \% \mathrm{CGFe}$ and the TGF- $\beta 1$ groups, it was observed that the ratios of p-ERK1/2 to ERK1/2, p-JNK to JNK and p-p38 to p38 were almost identical at 0, 30, 60 and $90 \mathrm{~min}$, and there were no statistically significant changes observed (data not shown).

\section{Discussion}

The main components of CGFe include epidermal growth factor, PDGF, fibroblast growth factor, bone morphogenetic protein and VEGF $(17,18)$. These growth factors display functions in accelerating the revascularization of injured tissues and inducing the differentiation, proliferation and migration of fibroblasts and osteoblasts $(19,20)$. In recent years, CGFe has been widely applied to the reconstruction of bone tissue in dental practice $(7,18,19)$.

Animal experiments indicated that TGF- $\beta 1$ could accelerate the healing of skull defects and tibia fractures, as well as strengthen the new bone tissue $(21,22)$. Chitosan scaffolds carrying TGF- $\beta 1$ were used in direct pulp capping of canine teeth, and the results indicated that TGF- $\beta 1$ promoted the formation of regenerative dentin (23). The non-collagen components of the extracellular matrix of bone tissue include core proteoglycan, disaccharide chain proteoglycan, bone mucin, BSP, OCN and osteopontin, among which BSP is the most important (24). TGF- $\beta 1$ upregulates the expression of BSP in dental pulp cells and promotes the formation of regenerative dentin (24). 


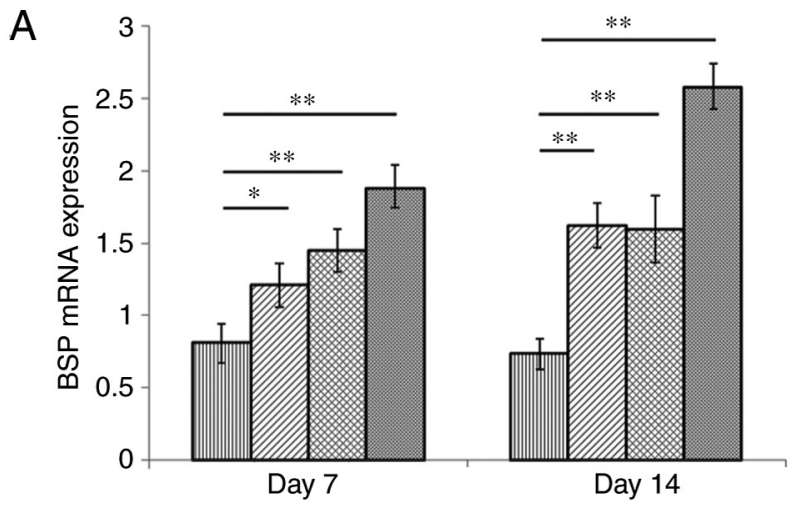

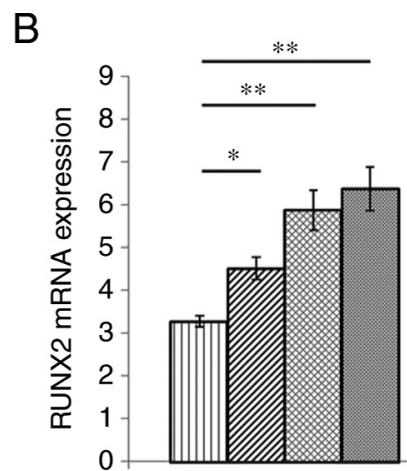

Day 7

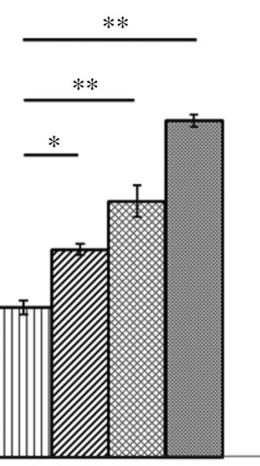

Day 14

C

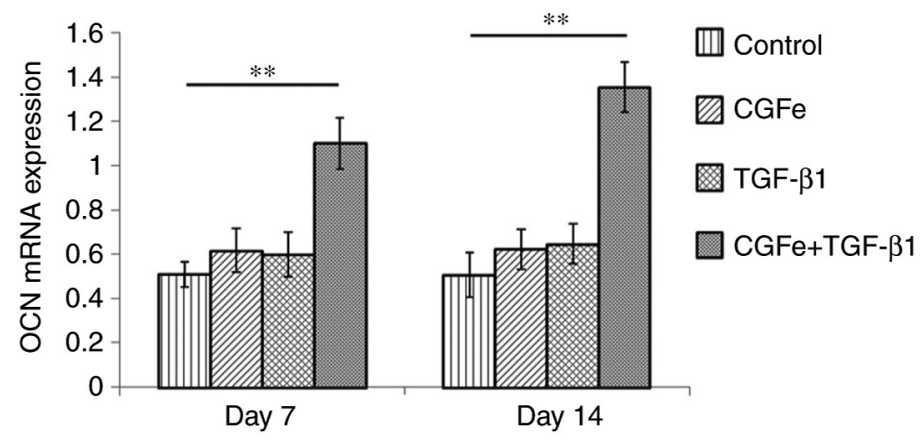

Figure 4. Reverse transcription-quantitative PCR examining the expression of the osteogenesis-related genes. (A) $B S P$ mRNA expression on the 7 and 14th days. (B) RUNX2 mRNA expression on the 7 and 14th days. (C) OCN mRNA expression on the 7 and 14th days. On the 7 and 14 th days, the expression levels of $B S P, R U N X 2$ and $O C N$ in the $100 \%$ CGFe + TGF- $\beta 1(1 \mathrm{ng} / \mathrm{ml})$ group were at the highest level. ${ }^{*} \mathrm{P}<0.05,{ }^{* *} \mathrm{P}<0.01$.

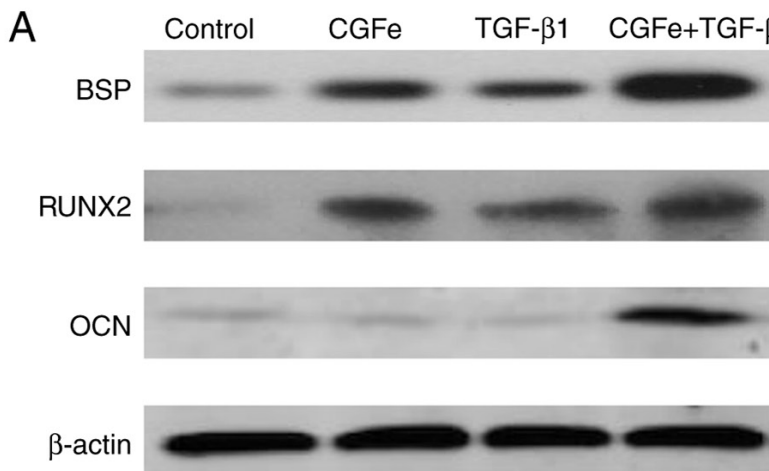

B

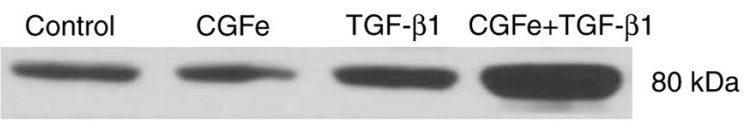

C
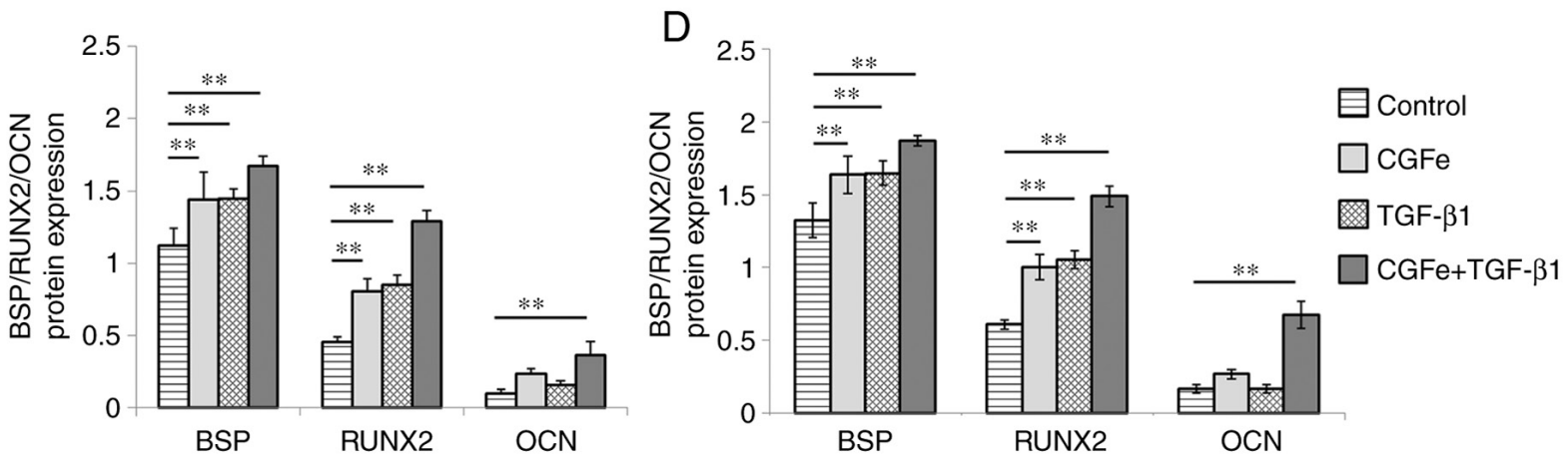

Figure 5. Analysis of $B S P, R U N X 2$ and $O C N$ protein expression in human dental pulp stem cells via western blotting. Cells were treated with various culture conditions for (A) 7 days and (B) 14 days. $\beta$-actin was used to monitor equal protein loading. The size of $B S P(80 \mathrm{kDa}), O C N(11 \mathrm{kDa}), R U N X 2(55 \mathrm{kDa})$ and of the loading control protein $\beta$-actin $(42 \mathrm{kDa})$ are indicated on the figure. Quantitative analysis of western blot expression of the proteins $B S P, R U N X 2$ and $O C N$ after (C) 7 days and (D) 14 days. The levels of $R U N X 2$ and $B S P$ were increased in the $100 \% \mathrm{CGFe}$, the TGF- $\beta 1$ (1 ng/ml) and the $100 \%$ CGFe + TGF- $\beta 1(1 \mathrm{ng} / \mathrm{ml})$ group. The level of $O C N$ was increased in the $100 \%$ CGFe + TGF- $\beta 1(1 \mathrm{ng} / \mathrm{ml})$ group but was not significantly increased in the $100 \%$ CGFe and the TGF- $\beta 1(1 \mathrm{ng} / \mathrm{ml})$ groups compared with the control group $(\mathrm{P}>0.05) .{ }^{* *} \mathrm{P}<0.01$. CGFe, concentrated growth factor exudate; $B S P$, bone sialoprotein; $R U N X 2$, Runt-related transcription factor 2; OCN, osteocalcin. 
A

p-ERK1/2 $=$

ERK1/2

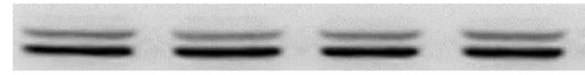

$\beta$-actin

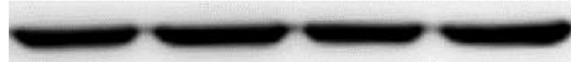

B

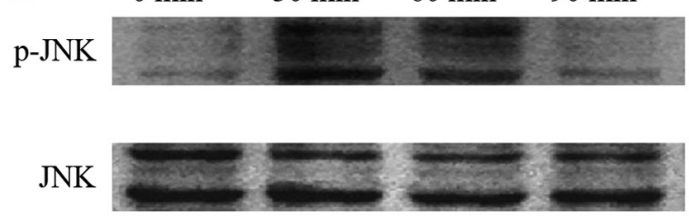

$\beta$-actin

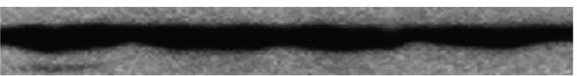

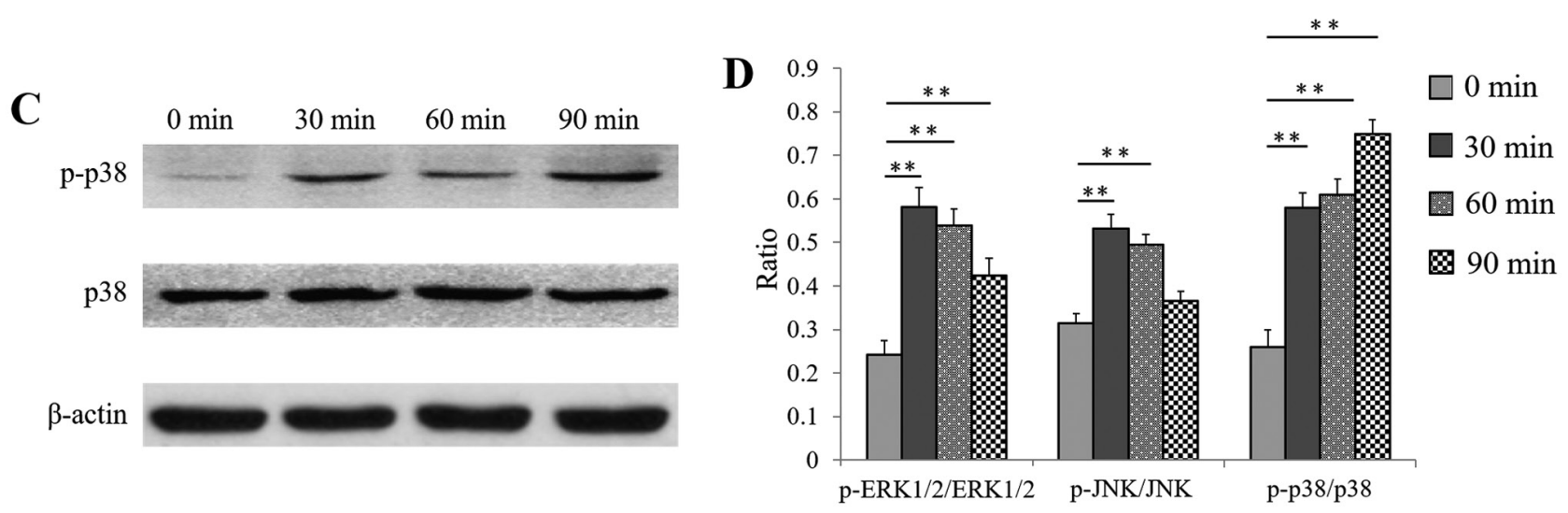

Figure 6. Expression of MAPK pathway proteins examined via western blotting in hDPSCs. $\beta$-actin was used to monitor equal protein loading. (A) Protein expression of p-ERK1/2 and ERK1/2, (B) p-JNK and JNK and (C) p-p38 and p38 at 30, 60 and 90 min after treatment with 100\% CGFe + TGF- $\beta 1$ (1 ng/ml). (D) The ratio of p-ERK1/2 to ERK1/2 in hDPSCs increased significantly after stimulation with CGFe + TGF- $\beta 1$ for 30 min and decreased slightly after 60 and $90 \mathrm{~min}$. The ratio of p-JNK to JNK in hDPSCs was also increased after stimulation with CGFe + TGF- $\beta 1$ for 30 and 60 min, and returned to its initial expression after $90 \mathrm{~min}$. The ratio of p-p38 to p38 in hDPSCs increased progressively after stimulation with CGFe + TGF- $\beta 1$ for 90 min, with the highest increase at $90 \mathrm{~min}$. ${ }^{* *} \mathrm{P}<0.01$. hDPSCs, human dental pulp stem cells; $\mathrm{p}$, phosphorylated.

RUNX2 is major bone transcription factors necessary for osteogenic differentiation (25). RUNX2 has been indicated to induce osteogenic gene expression and biological mineral deposition in primary dermal fibroblasts (26), while directly regulating the expression of craniosynostosis-associated genes and skeletal tissue-enriched genes (26). Overexpression of RUNX2 in adipose tissue-derived mesenchymal stem cells triggered their osteoblastic differentiation (25). RUNX2 knockout mice demonstrated a complete lack of bone formation due to the maturation arrest of osteoblasts $(25,26)$. OCN expression is used as a marker of osteoblast metabolic activity and mineral deposition in osteoblast cultures (26). In the present study, the finding that TGF- $\beta 1$ induced the upregulation of RUNX2, BSP and $O C N$ gene expression in hDPSCs suggested that TGF- $\beta 1$ acts as an important stimulatory factor during osteogenesis and odontogenesis.

The present study reported that $100 \%$ CGFe + TGF- $\beta 1$ induced the highest increase in hDPSC viability, compared with the control group. Bone formation and odontogenic differentiation of hDPSCs was also notably enhanced in the $\mathrm{CGFe}+\mathrm{TGF}-\beta 1$ group, which was evidenced by the increased ALP activity and the higher expression of bone formation and odontogenic markers, compared with the control group. It was observed that CGFe + TGF- $\beta 1$ upregulated the expression of p-ERK1/2, p-JNK and p-p38 in hDPSCs, indicating that it activated MAPK pathways during the osteogenic and odontogenic differentiation of hDPSCs. The present experiments indicated that CGFe + TGF- $\beta 1$ promoted the viability, as well as the osteogenic and odontogenic differentiation of hDPSCs via the activation of the MAPK pathway, indicating that the factors included in CGFe and TGF- $\beta 1$ played important roles during osteogenic differentiation and could have clinical implications in dental pulp regeneration and osteoporosis. The findings of the present study suggested that CGF + TGF- $\beta 1$-treated hDPSCs may potentially be used for bone and tooth regeneration.

Subsequent studies may be carried out to explore other pathway mechanisms involved in the differentiation of hDPSCs stimulated by CGFe and TGF- $\beta 1$. Further investigation of microRNA expression during $\mathrm{CGFe}+\mathrm{TGF}-\beta 1$-mediated differentiation may facilitate the in vivo applications of CGFe and TGF- $\beta 1$ in bone and dental tissue engineering in the future.

In conclusion, the present study demonstrated that CGFe together with TGF- $\beta 1$ facilitated the viability and osteogenic differentiation of hDPSCs through the activation of the MAPK signaling pathway, suggesting that CGFe and TGF- $\beta 1$ play important roles in the osteogenic differentiation process. The present work provided insights for the application of CGFe and TGF- $\beta 1$ in periodontal tissue regeneration and alveolar bone remodeling.

\section{Acknowledgements}

Not applicable.

\section{Funding}

The present study was supported by Shenzhen Fundamental Research Program (grant no. JCYJ20180228164057158), the 
Longhua District Health Bureau of Shenzhen Municipality (grant no. 2020017) and the Guangzhou Health Science and technology project (grant no. 20211A011100).

\section{Availability of data and materials}

The datasets used and/or analyzed during the current study are available from the corresponding author on reasonable request.

\section{Authors' contributions}

XL, HY, XD and ZY conceived and designed the study. XL, $\mathrm{ZY}$ and $\mathrm{YZ}$ performed cell culture, immunostaining and viability analysis. XL, XD and YZ performed the experimental procedures of osteogenic differentiation induction, reverse transcription-quantitative PCR and western blotting. $\mathrm{HY}, \mathrm{XD}, \mathrm{BW}$ and $\mathrm{JL}$ provided reagents and interpreted the data. XL, HY, XD, ZY and JL performed data analysis and wrote the manuscript. ZY and BW confirm the authenticity of all the raw data. All authors have read and approved the final manuscript.

\section{Ethics approval and consent to participate}

The present study was approved by the Ethics Committee of the Stomatological School of Jilin University Health Science Center (Changchun, China). Written informed consent was obtained from all participants or their parents prior to experimentation.

\section{Patient consent for publication}

Not applicable.

\section{Competing interests}

The authors declare that they have no competing interests.

\section{References}

1. Chen FM and Yan J: Periodontal tissue engineering and regeneration: Current approaches and expanding opportunities. Tissue Eng Part B Rev 16: 219-255, 2010.

2. Bosshardt DD and Sculean A: Does periodontal tissue regeneration really work? Periodontol 5: 208-219, 2009.

3. Mey AH, Yu ZD and Huang TJ: Small molecules affect human dental pulp stem cell properties via multiple signaling pathways. Stem Cells Dev 22: 2402-2413, 2013.

4. Yu J, Deng Z, Shi J, Zhai H, Nie X, Zhuang H, Li Y and Jin Y: Differentiation of dental pulp stem cells into regular-shaped dentin-pulp complex induced by tooth germ cell conditioned medium. Tissue Eng 12: 3097-3105, 2006.

5. Wang Y, Li J, Song W and Yu J: Mineral trioxide aggregate upregulates odonto/osteogenic capacity of bone marrow stromal cells from craniofacial bones via JNK and ERK MAPK signalling pathways. Cell Prolif 47: 241-248, 2014.

6. Zhang W, Shen X, Wan C, Zhao Q, Zhang L, Zhou Q and Deng L: Effects of insulin and insulin-like growth factor 1 on osteoblast proliferation and differentiation: Differential signalling via Akt and ERK. Cell Biochem Funct 30: 297-302, 2012.

7. Kim TH, Kim SH, Sándor GK and Kim YD: Comparison of platelet-rich plasma (PRP), platelet-rich fibrin (PRF), and concentrated growth factor (CGF) in rabbit-skull defect healing. Arch Oral Biol 59: 550-558, 2014.
8. Park HC, Kim SG, Oh JS, You JS, Kim JS, Lim SC, Jeong MA, Kim JS, Jung C, Kwon YS and Ji H: Early bone formation at a femur defect using CGF and PRF grafts in adult dogs: A comparative study. Implant Dent 25: 387-393, 2016.

9. Chin D, Boyle GM, Parsons PG and Coman WB: What is transforming growth factor-beta (TGF-beta)?. Br J Plast Surg 57: 215-221, 2004.

10. Kubiczkova L, Sedlarikova L, Hajek R and Sevcikova S: TGF- $\beta$ an excellent servant but a bad master. J Transl Med 10: 183, 2012.

11. Tang Y, Wu X, Lei W, Pang L, Wan C, Shi Z, Zhao L, Nagy TR, Peng X, Hu J, et al: TGF-beta1-induced migration of bone mesenchymal stem cells couples bone resorption with formation. Nat Med 15: 757-765, 2009

12. Vahabi S, Torshabi M and Nejad AE: In vitro comparison of the efficacy of TGF- $\beta 1$ and PDGF-BB in combination with freeze-dried bone allografts for induction of osteogenic differention in MG-63 osteoblast-like cells. J Mater Sci Mater Med 27: 182, 2016.

13. Farea M, Husein A, Halim AS, Abdullah NA, Mokhtar KI, Lim CK, Berahim Z and Mokhtar K: Synergistic effects of chitosan scaffold and TGF $\beta 1$ on the proliferation and osteogenic differentiation of dental pulp stem cells derived from human exfoliated deciduous teeth. Arch Oral Biol 59: 1400-1411, 2014.

14. Yu J, He H, Tang C, Zhang G, Li Y, Wang R, Shi J and Jin Y: Differentiation potential of STRO- $1^{+}$dental pulp stem cells changes during cell passaging. BMC Cell Biol 11: 32, 2010.

15. Li X, Yang H, Zhang Z, Yan Z, Lv H, Zhang Y and Wu B: Concentrated growth factor exudate enhances the proliferation of human periodontal ligament cells in the presence of TNF- $\alpha$. Mol Med Rep 19: 943-950, 2019.

16. Livak KJ and Schmittgen TD: Analysis of relative gene expression data using real-time quantitative PCR and the 2(-Delta Delta C(T)) method. Methods 25: 402-408, 2001.

17. Qiao J, Duan J, Zhang Y, Chu Y and Sun C: The effect of concentrated growth factors in the treatment of periodontal intrabony defects. Future Sci OA 2: FS136, 2016.

18. Rodella LF, Favero G, Boninsegna R, Buffoli B, Labanca M, Scarì G, Sacco L, Batani T and Rezzani R: Growth factors, CD34 positive cells, and fibrin network analysis in concentrated growth factors fraction. Microsc Res Tech 74: 772-777, 2011.

19. Honda H, Tamai N, Naka N, Yoshikawa N and Myoui A: Bone tissue engineering with bone marrow-derived stromal cells integrated with concentrated growth factor in rattus norvegicus calvaria defect model. J Artif Organs 16: 305-315, 2013.

20. Shinohara Y, Tsuchiya S, Hatae K and Honda MJ: Effect of vitronectin bound to insulin-like growth factor-I and insulin-like growth factor binding protein-3 on porcine enamel organ-derived epithelial cells. Int J Dent 2012: 386282, 2012.

21. Sarahrudi K, Thomas A, Mousavi M, Kaiser G, Köttstorfer J, Kecht M, Hajdu S and Aharinejad S: Elevated transforming growth factor-beta 1 (TGF- $\beta 1$ ) levels in human fracture healing. Injury 42: 833-837, 2011.

22. Poniatowski LA, Wojdasiewicz P, Gasik R and Szukiewicz D. Transforming growth factor beta family: Insight into the role of growth factors in regulation of fracture healing biology and potential clinical application. Mediators Inflamm 2015: 137823, 2015.

23. Li F, Liu X, Zhao SL, Wu H and Xu HHK: Porous chitosan bilayer membrane containing TGF- $\beta 1$ loaded microspheres for pulp capping and reparative dentin formation in a dog model. Dent Mater 30: 172-181, 2014.

24. Hwang YC, Hwang IN, Oh WM, Park JC, Lee DS and Son HH: Influence of TGF-betal on the expression of BSP,DSP, TGF-beta1 receptor I and smad proteins during reparative dentinogenesis. J Mol Hist 39: 153-160, 2008

25. Chen Q, Liu WB, Sinha KM, Yasuda H and de Crombrugghe B: Identification and characterization of microRNAs controlled by the osteoblast-specific transcription factor osterix. PLoS One 8: e58104, 2013.

26. Jeong W, Song G, Bazer FW and Kim J: Insulin-like growth factor I induces proliferation and migration of porcine trophectoderm cells through multiple cell signaling pathways, including protooncogenic protein kinase 1 and mitogen-activated protein kinase. Mol Cell Endocrinol 384: 175-184, 2014.

This work is licensed under a Creative Commons Attribution-NonCommercial-NoDerivatives 4.0 International (CC BY-NC-ND 4.0) License. 